\title{
ERTES SIMPLIFICADOS Y RÁPIDOS: A MEDIDA DEL COVID-19
}

Fco. Ramón Lacomba Pérez

Abogado del Área de Gestión de Conocimiento de Cuatrecasas

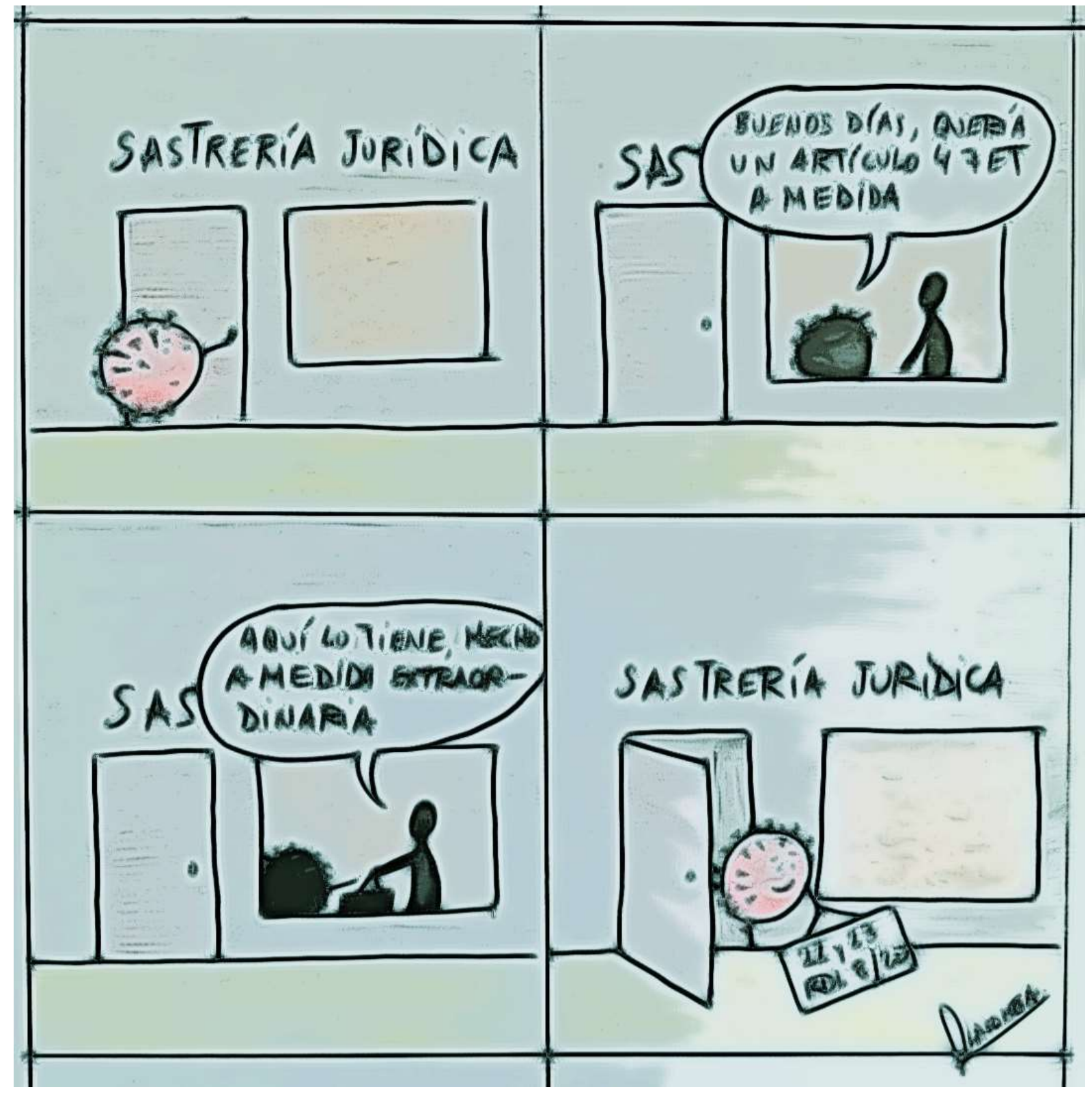

IUSLabor 1/2020, ISSN 1699-2938, p. 39-44

DOI. 10.31009/IUSLabor.2020.i01.02

Fecha envío: 13.4.2020 | Fecha aceptación: 15.4.2020 


\section{Abstract}

Como consecuencia de la pandemia del COVID-19 el Gobierno ha modificado la regulación del ERTE como mecanismo de flexibilidad interna, incentivado la respuesta laboral de las empresas frente a esta abrupta parálisis de la actividad, agudizada por la declaración de estado de alarma y otras medidas gubernamentales de contención. En el presente artículo se analizan brevemente las principales medidas adoptadas respecto del ERTE.

As a consequence of the COVID-19 pandemic, the Government has modified the regulation of the temporary employment regulation proceedings as a mechanism of internal flexibility, encouraging the labor response of companies in the face of this abrupt paralysis of activity, exacerbated by the declaration of alarm status and other measures. government containment. This article briefly analyzes the main measures adopted with respect to the temporary employment regulation proceedings.

Title: Simplified and fast temporary employment regulation proceedings: tailored to COVID-19

Palabras clave: ERTEs, suspensión de contrato, COVID-19, fuerza mayor, causas económicas, técnicas, organizativas o de producción.

Keywords: temporary employment regulation proceedings, suspension labor contract, COVID-19, force majeure, economic, technical, organizational and productive causes.

\section{Sumario}

1. Introducción

2. Medidas excepcionales adoptadas en materia de ERTEs

2.1. Agilizar el inicio del ERTE por fuerza mayor

2.2. Facilitar la interlocución en los ERTEs por causas objetivas en empresas sin representación unitaria

2.3. Reducir plazos

2.4. Obviar algún mecanismo de control

2.5. Agilizar la tramitación y abono de prestaciones por desempleo 


\section{Introducción}

La circunstancia de que sobrevenga a la empresa una fase temporal de desequilibrio económico, una caída transitoria de volumen de trabajo (y el consiguiente exceso puntual de capacidad productiva) o una ineficiencia organizativa provisional, o incluso un impedimento total o parcial a su actividad por fuerza mayor temporal, es un escenario nada novedoso, para el que el sector laboral del ordenamiento jurídico provee ya desde antiguo de una respuesta protectora conocida.

En concreto, para estos casos, y puesto que se trata de una situación a priori reversible, está previsto proteger la continuidad del empleo mediante la suspensión de los contratos de trabajo, a través del denominado ERTE (expediente de regulación temporal de empleo): un procedimiento de consulta con la representación de los trabajadores e información a la Autoridad Laboral, que se desarrolla dentro de los plazos y en los términos previstos en el artículo 47 ET y los artículos 16 a 29 del Real Decreto 1483/2012. Ello salvo que se trate de un impedimento para la prestación laboral derivado de una fuerza mayor temporal, en cuyo caso, no se requiere negociación alguna con la representación social, sino que, con carácter previo, la empresa solicite a la Autoridad Laboral que constate la existencia de esa situación de fuerza mayor (artículos 31 a 33 Real Decreto 1483/2012).

Con todo y ser este expediente de suspensión un mecanismo de flexibilidad interna ya previsto y más ágil que el procedimiento de despido colectivo, su capacidad de respuesta ha debido mejorarse para hacer frente al aluvión sin precedentes de suspensiones de contratos de trabajo hacia donde el Gobierno ha incentivado la respuesta laboral de las empresas frente a esta abrupta parálisis de la actividad, derivada de la pandemia del COVID-19, y agudizada por la declaración de estado de alarma (desde el 14 de marzo de 2020, merced al Real Decreto 463/2020) y otras medidas gubernamentales de contención.

\section{Medidas excepcionales adoptadas en materia de ERTEs}

Particularmente, el legislador de urgencia ha debido adoptar medidas excepcionales para ganar velocidad en la tramitación de estos procedimientos dirigidos a la suspensión de contratos de trabajo. En concreto, ha agilizado las comunicaciones en el inicio del procedimiento, ha facilitado la interlocución, ha sacrificado plazos máximos y mecanismos de control y ha trasladado a las empresas alguna parte de la gestión subsiguiente a la suspensión de los contratos (concretamente, la solicitud de la prestación por desempleo de sus trabajadores). Todo ello, y ante la precipitación de las medidas, se ha debido acompañar de un fuerte despliegue de guías, 
instrucciones y notas interpretativas emitidas, casi sin aliento, desde la Dirección General de Trabajo dependiente del Ministerio de Trabajo y desde el Servicio Público de Empleo Estatal (SEPE).

Veamos resumidamente esos cinco grupos de medidas flexibilizadoras de los ERTEs adoptadas en este contexto de crisis sanitaria.

\subsection{Agilizar el inicio del ERTE por fuerza mayor}

En primer lugar, de acuerdo con el artículo 22 Real Decreto-Ley 8/2020, cuando la fuerza mayor que se solicita constatar derive de los efectos del Covid-19, la norma va a procurar un arranque más dirigido y directo del procedimiento de ERTE, guiando en la documentación a aportar e imponiendo que se informe directamente a los trabajadores afectados:

1) Por una parte, se introduce un dictado más preciso sobre cómo debe proceder documentalmente la empresa, al concretarle la forma de acreditación de la causa de fuerza mayor: pasa la norma de una referencia amplia a que se acompañen a la solicitud "los medios de prueba que estime necesarios", a indicar expresamente al menos uno de los documentos a aportar, esto es, un informe relativo a la vinculación de la pérdida de actividad como consecuencia del COVID-19 (artículo 10 y anexo RD 463/2020), así como en su caso, documentación acreditativa.

2) Por otra parte, se impone que se haga llegar antes la información a los trabajadores, pasando de que la empresa deba comunicar la solicitud de forma simultánea a los representantes legales de los trabajadores, a que deba comunicarla de forma simultánea a los trabajadores y, en el caso de que existan representantes, también deba dar traslado a estos del informe anterior $y$ documentación acreditativa.

\subsection{Facilitar la interlocución en los ERTEs por causas objetivas en empresas sin representación unitaria}

Por otra parte, en el caso de los ERTEs por causas económicas, técnicas, organizativas o de producción derivadas del COVID-19, en empresas sin ningún representante unitario en ningún centro de trabajo, la norma procura un trámite más ejecutivo en orden a designar a la comisión representativa de los trabajadores. 
En concreto, el artículo 23 Real Decreto-Ley 8/2020 elimina la opción de escoger entre una comisión integrada por trabajadores de la propia empresa (elegida democráticamente) o a una comisión de componentes designados por sindicatos más representativos y representativos del sector, con un número de entre 1 y 3 miembros, prevista en el ERTE ordinario; e impone aquí a los trabajadores una única vía: una comisión representativa integrada por un miembro de cada sindicato más representativo y representativo del sector y, en caso de no conformarse, una comisión integrada por 3 trabajadores (no menos) elegidos democráticamente.

\subsection{Reducir plazos}

Adicionalmente, en los ERTEs por causas objetivas derivadas del COVID-19, el artículo 23 Real Decreto-Ley 8/2020 acorta dos plazos de los establecidos con carácter general en este tipo de procedimientos:

- Por una parte, reduce el plazo máximo para la conformación de la comisión representativa de los trabajadores en ausencia de representación unitaria, que pasa de 15 días a 5 días.

- Por otra parte, comprime la duración máxima del período de consultas, que de un límite de 15 días pasa a 7 días

Y, en la misma línea, tanto en los ERTEs por fuerza mayor como en los debidos a causas económicas, técnicas, organizativas o productivas, el informe de la Inspección de Trabajo que, en su caso, pueda solicitar la Autoridad Laboral ve también reducidos sus plazos de emisión:

- En los ERTEs por fuerza mayor, donde no se establece ningún plazo máximo, se impone ahora un límite máximo de 5 días.

- En los ERTEs por causas objetivas, en los que el indicado informe de la Inspección de Trabajo puede demorarse hasta 15 días, deberá evacuarse ahora en un plazo máximo de 7 días.

\subsection{Obviar algún mecanismo de control}

Otra de las medidas excepcionales adoptadas para simplificar el trámite de los ERTEs, tanto por fuerza mayor como por causas objetivas, cuando están en el tejado de la Autoridad Laboral, ha sido dejar a su criterio discrecional si insta o no el informe de la Inspección de Trabajo, es decir, convertirlo en potestativo. 
Ello supone que en los casos en los que Administración no advierta inicialmente elementos de duda acerca de la causa, la negociación o los términos de la conclusión del ERTE, prescindirá de este trámite, ganando con ello velocidad a la hora de despejar el camino al SEPE.

\subsection{Agilizar la tramitación y abono de prestaciones por desempleo}

Por último, en ambos tipos de ERTEs vinculados al COVID-19, los trabajadores afectados por la suspensión de sus contratos tienen derecho a unas prestaciones extraordinarias por desempleo, sin carencia exigida y a reponer por el SEPE.

En el acceso a dichas prestaciones es donde desemboca, finalmente, el procedimiento de suspensión de contratos llevado a cabo y, ante el riesgo de colapso de la Administración derivado del ingente volumen de expedientes, ha buscado el legislador de urgencia neutralizar la demora adicional que pueda producirse en el trámite y percibo de las mismas por los trabajadores. Para ello, la medida simplificadora que ha introducido el artículo 3 Real Decreto-Ley 9/2020 consiste en convertir a la empresa en responsable de la solicitud ante el SEPE de las prestaciones por desempleo de sus trabajadores afectados.

Concretamente, en el plazo de 5 días hábiles desde la solicitud del ERTE por fuerza mayor o desde la fecha en que la empresa notifique a la Autoridad Laboral competente su decisión en el caso de los ERTEs por causas objetivas, derivados ambos del COVID-19, la empresa deberá remitir al SEPE a través de medios electrónicos y en la forma que se determine por la entidad gestora, en nombre de sus trabajadores (previo su consentimiento expreso), una solicitud colectiva de sus prestaciones por desempleo. Ello so pena de incurrir en infracción grave prevista en el artículo 22.13 del texto refundido de la Ley sobre Infracciones y Sanciones en el Orden Social, aprobado por el Real Decreto Legislativo 5/2000, de 4 de agosto. 